\title{
COMPORTAMENTO DE CULTIVARES DE FEIJOEIRO-COMUM EM SISTEMA CONVENCIONAL E PLANTIO DIRETO COM DIFERENTES PALHADAS ${ }^{1}$
}

\author{
Performance of common beans cultivars in both \\ conventional and no-tillage systems using different straws \\ Raimundo Luíz Laurinho dos Santos ${ }^{2}$, João Batista Donizete Corrêa ${ }^{3}$, \\ Messias José Bastos de Andrade ${ }^{4}$, Augusto Ramalho de Morais ${ }^{5}$
}

\begin{abstract}
RESUMO
Para estudar o comportamento agronômico de cultivares de feijoeiro-comum, de diferentes grupos comerciais, em sistema convencional e em plantio direto sobre diferentes coberturas do solo, foram conduzidos em Lavras-MG quatro experimentos de campo, em três safras. Nos três primeiros, estudaram-se seis cultivares (Ouro Negro, Talismã, Carioca, Pérola, Roxão e Jalo ESAL) e quatro sistemas de plantio (plantio direto sobre as palhadas de aveia, trigo, resteva do pousio, mais o plantio convencional). O delineamento estatístico foi em blocos casualizados com quatro repetições e esquema experimental em faixas. No quarto experimento, adotaram-se o mesmo delineamento e as mesmas cultivares, mas os sistemas foram apenas três (plantio direto sobre palhadas de aveia e resteva do pousio, mais o sistema convencional). Avaliaram-se, em cada safra, as quantidades de palha no plantio direto, o estande final e o rendimento de grãos do feijoeiro. O comportamento do rendimento de grão e o estande final do feijoeiro são modificados pelo sistema de plantio e principalmente pelas safras. De modo geral, a cultivar Ouro Negro, de grãos pretos, é mais produtiva que as cultivares de grão carioca (Talismã, Carioca e Pérola). As cultivares de grãos maiores (Jalo ESAL e Roxão) tiveram o pior comportamento. Nos ambientes mais favoráveis, o plantio direto suplanta o sistema convencional. Em solo com pequena quantidade de palha e turnos de irrigação espaçados entre três ou quatro dias, o plantio direto sobre resteva do pousio propicia maior rendimento de grãos.
\end{abstract}

Termos para indexação: Phaseolus vulgaris, aveia, trigo, plantio direto, palhada do pousio.

\section{ABSTRACT}

Four field experiments were carried out in Lavras (south region of Minas Gerais State) during three seeding seasons whit the purpose of studying the agronomical performance of common beans cultivars from different commercial groups by using both the conventional and no-tillage systems on different soil coats. The treatments were arranged in a split block schema. A randomized block design was used with four replications. In the first three experiments, six cultivars (Ouro Negro, Talismã, Carioca, Pérola, Roxão and Jalo ESAL) and four planting systems (conventional and no-tillage on oat, wheat and bare soil straw) were used in the treatments. The same statistical design and the same cultivars were used in the fourth experiment. However, only three planting systems (conventional and no-tillage on oat and bare soil straws) were used. The amount of straw used in notillage system, as well as the beans plants and the grain yield, was estimated. The beans cultivars agronomical performances were modified by the planting system, especially by the seeding seasons. In general, the black-grain Ouro Negro cultivar has performed better than the carioca-grain ones (Talismã, Carioca, and Pérola). The cultivars with the biggest grains were those that have had the worst performance. The highest grain yields were achieved in the winter-spring irrigated season, followed by the rain season, and finally the dry season. At more favorable environmental conditions the no-tillage system was found to surpass the conventional one. The no-tillage on bare soil straw promotes better grain yield at less favorable environmental conditions.

Index terms: Phaseolus vulgaris, oat, wheat, no-tillage, bare soil straw.

(Recebido para publicação em 24 de setembro de 2003 e aprovado em 26 de agosto de 2004)

\footnotetext{
1. Parte de dissertação apresentada pelo primeiro autor à Universidade Federal de Lavras/UFLA - Caixa Postal 3037 - $37200-000$ - Lavras, MG. Mestrado em Agronomia/Fitotecnia.

2. Licenciado Pleno em Agropecuária, MSc., Professor da Escola Agrotécnica Federal de São Cristóvão - Av. Adélia Franco, 2850 , Bloco 1, aptº 401 - Jardim América Luzia - Aracaju, SE. luizlaurinho@bol.com.br.

3. Engenheiro Agrônomo, DSc., Professor Adjunto do Departamento de Agricultura da UFLA.

4. Engenheiro Agrônomo, DSc., Professor Adjunto do Departamento de Agricultura da UFLA, bolsista do CNPq

5. Engenheiro Agrônomo, DSc., Professor Adjunto do Departamento de Ciências Exatas da UFLA, bolsista do CNPq.
} 


\section{INTRODUÇÃO}

Além do café e do leite, o milho e o feijão são as principais explorações agropecuárias do sul de Minas Gerais, onde os produtores têm procurado estabelecer sistemas de produção mais intensivos, como a rotação milhosilagem/feijão-seca ou milho-grão/feijão-invemo, esse último restrito às propriedades que dispõem de irrigação. Outra alternativa é a exploração de milho verde, que produz palha com retorno econômico, amortiza custos (especialmente nas fases de implantação do plantio direto) e permite o cultivo do feijão da seca em sucessão. Há, entretanto, necessidade de se estudar para a região outras sequiências culturais, como opções para a adoção do plantio direto.

A rotação de culturas, além do cultivo de feijão e milho, deve introduzir outras, como trigo, aveia, sorgo ou cevada, que poderão ser destinadas ao comércio ou somente contribuir para formação da palhada (SILVA, 1996; MACHADO, 2000). A rotação com culturas comerciais tem dificultado a formação da camada orgânica sobre o solo, pois, dependendo da espécie e do seu manejo, não há produção de fitomassa suficiente. Outras dificuldades são as condições adversas, tais como ausência de chuvas, baixas temperaturas durante o inverno, rápida decomposição da palhada no período de verão e alelopatia (ALVARENGA et al., 2001; OLIVEIRA, 2001). Além da rotação, uma boa opção é aproveitar o pousio de inverno, situação típica nas propriedades mineiras, pois a resteva, sem maiores cuidados, pode se transformar em razoável palhada.

É interessante observar ainda que além da especificidade das condições edafoclimáticas, o aumento da produtividade depende da cultivar. Altas produtividades só serão conseguidas se o uso correto das práticas de manejo for aliado à escolha criteriosa da cultivar (CIRINO et al., 2000).

Objetivou-se com o presente trabalho avaliar cultivares de feijoeiro-comum, de diferentes grupos comerciais, em sistema convencional e em plantio direto, sobre diferentes coberturas do solo em três safras do sul de Minas Gerais.

\section{MATERIAL E MÉTODOS}

Foram conduzidos quatro experimentos de campo (águas 2001/2002, inverno-primavera 2002, águas 2002/2003 e seca 2003), em área experimental do Departamento de Agricultura (DAG) da Universidade Federal de Lavras (UFLA), em um LATOSSOLO VERMELHO Distroférrico típico - LVdt (EMBRAPA, 1999), conforme Tabela 1.
Lavras situa-se no sul de Minas Gerais $\left(21^{\circ} 14^{\prime}\right.$ de latitude sul e $45^{\circ} 00^{\prime}$ de longitude oeste), a $910 \mathrm{~m}$ sobre o nível do mar (BRASIL, 1992). As ocorrências climáticas diárias, durante a condução dos experimentos, são apresentadas na Figura 1.

O delineamento estatístico foi de blocos casualizados com quatro repetições e tratamentos dispostos em faixas. Nas três primeiras safras, os tratamentos envolveram seis cultivares de feijoeiro-comum (Jalo ESAL, Ouro Negro, Pérola, Carioca, Talismã e Roxão, caracterizadas na Tabela 2) e quatro sistemas de plantio (plantio direto com palhadas de aveia, de trigo e resteva de pousio, mais o plantio convencional).

$\mathrm{Na}$ última safra (seca 2003), adotaram-se o mesmo delineamento e as mesmas cultivares, mas os sistemas de plantio foram apenas três (palhadas de aveia e do pousio, mais o sistema convencional). As parcelas foram constituídas por quatro fileiras (duas úteis) de feijoeiros espaçadas de 0,50 $\mathrm{m}$, com 4,0 $\mathrm{m}$ de comprimento.

As áreas destinadas ao plantio direto foram demarcadas em gleba explorada com esse sistema há mais de três anos e que se encontrava subdividida, com as culturas de aveia e trigo, além de parte em pousio. As semeaduras de trigo e aveia antecederam o plantio do feijão em cerca de cinco meses. A cultivar de trigo foi a BR 26 São Gotardo e, no caso da aveia, a área foi ocupada com aproximadamente 20 cultivares pertencentes a um ensaio nacional de rendimento.

A semeadura de trigo foi mecânica, com espaçamento entre linhas de $0,17 \mathrm{~m}$ e 70 sementes por metro. No caso da aveia, a semeadura foi manual, no mesmo espaçamento, com 80 sementes por metro. A adubação de plantio foi de $250 \mathrm{~kg} \mathrm{ha}^{-1}$ do formulado 4-30-16 e a cobertura de $100 \mathrm{~kg} \mathrm{ha}^{-1}$ de uréia, no perfilhamento. $\mathrm{O}$ controle de plantas daninhas foi feito em pós-emergência com 2,4 D (Esteron $400 \mathrm{BR}, 1 \mathrm{~L}$ $\mathrm{ha}^{-1}$ ), na época do perfilhamento. A colheita dos cereais ocorreu entre 110 e 120 dias após o plantio.

A calagem foi realizada sempre 30 dias antes da semeadura, utilizando-se o método da saturação por bases, para calcular a quantidade de calcário (CFSEMG, 1999). Adotou-se $60 \%$ como valor mínimo para a saturação por bases, praticando-se calagem nas áreas em que esse valor mostrava-se inferior, sendo o calcário aplicado em superfície no sistema de plantio direto. A área do plantio convencional, também utilizada há mais de três anos com esse sistema, era adjacente às anteriores; o calcário foi incorporado por ocasião da aração. 
TABELA 1 - Análise química de amostras (profundidade de 0 a $20 \mathrm{~cm}$ ) do solo utilizado. UFLA, Lavras-MG.

\begin{tabular}{|c|c|c|c|c|c|c|c|c|}
\hline \multirow{2}{*}{ Características } & \multicolumn{2}{|c|}{ Águas 2001} & \multicolumn{2}{|c|}{ Inverno 2002} & \multicolumn{4}{|c|}{ Águas 2002 e Seca 2003* } \\
\hline & PD & $\mathrm{CO}$ & PD & $\mathrm{CO}$ & PDT & PDA & PDP & CO \\
\hline pH em água & 5,7 & 6,1 & 5,5 & 6,2 & 5,9 & 6,0 & 6,0 & 6,1 \\
\hline$P\left(\mathrm{mg} \mathrm{dm}^{-3}\right)$ & 9,3 & 5,8 & 4,0 & 5,8 & 7,8 & 6,5 & 7,1 & 2,0 \\
\hline $\mathrm{K}\left(\mathrm{mg} \mathrm{dm}^{-3}\right)$ & 70 & 89 & 44 & 125 & 116 & 75 & 83 & 23 \\
\hline $\mathrm{Ca}^{2+}\left(\mathrm{cmol}_{\mathrm{c}} \mathrm{dm}^{-3}\right)$ & 2,6 & 2,8 & 2,3 & 3,5 & 2,6 & 2,3 & 2,7 & 2,2 \\
\hline $\mathrm{Mg}^{2+}\left(\mathrm{cmol}_{\mathrm{c}} \mathrm{dm}^{-3}\right)$ & 0,4 & 1,1 & 0,1 & 1,0 & 0,3 & 1,1 & 0,3 & 0,3 \\
\hline $\mathrm{Al}^{3+}\left(\mathrm{cmol}_{\mathrm{c}} \mathrm{dm}^{-3}\right)$ & 0,0 & 0,0 & 0,1 & 0,0 & 0,1 & 0,1 & 0,1 & 0,1 \\
\hline $\mathrm{H}+\mathrm{Al}\left(\mathrm{cmol}_{\mathrm{c}} \mathrm{dm}^{-3}\right)$ & 2,9 & 2,3 & 3,6 & 2,1 & 2,1 & 2,3 & 2,1 & 2,1 \\
\hline $\mathrm{SB}\left(\mathrm{cmol}_{\mathrm{c}} \mathrm{dm}^{-3}\right)$ & 3,2 & 4,1 & 2,5 & 4,8 & 3,2 & 3,6 & 3,2 & 2,6 \\
\hline (t) $\left(\mathrm{cmol}_{\mathrm{c}} \mathrm{dm}^{-3}\right)$ & 3,2 & 4,1 & 2,6 & 4,8 & 3,3 & 3,7 & 3,3 & 2,7 \\
\hline$(\mathrm{T})\left(\mathrm{cmol}_{\mathrm{c}} \mathrm{dm}^{-3}\right)$ & 6,1 & 6,4 & 6,1 & 6,9 & 5,3 & 5,9 & 5,3 & 4,7 \\
\hline $\mathrm{V}(\%)$ & 52,3 & 64,2 & 41,1 & 69,7 & 60,4 & 61,0 & 60,5 & 54,9 \\
\hline $\mathrm{m}(\%)$ & 0 & 0 & 4 & 0 & 3 & 3 & 3 & 4 \\
\hline $\operatorname{MO}\left(\mathrm{dag} \mathrm{kg}^{-1}\right)$ & 2,4 & 2,2 & 2,5 & 2,9 & 2,0 & 2,4 & 2,1 & 2,1 \\
\hline P-rem $\left(\mathrm{mg} \mathrm{L}^{-1}\right)$ & 7,5 & 7,7 & 12,5 & 13,2 & 10,5 & 11,8 & 12,5 & 11,2 \\
\hline $\mathrm{Zn}\left(\mathrm{mg} \mathrm{dm}^{-3}\right)$ & - & - & 3,0 & 3,9 & 5,6 & 8,7 & 11,9 & 2,0 \\
\hline $\mathrm{Fe}\left(\mathrm{mg} \mathrm{dm}^{-3}\right)$ & - & - & 28,9 & 24,4 & 36,6 & 29,1 & 30,9 & 34,1 \\
\hline $\operatorname{Mn}\left(\mathrm{mg} \mathrm{dm}^{-3}\right)$ & - & - & 25,7 & 36,0 & 33,5 & 34,2 & 35,0 & 21,7 \\
\hline $\mathrm{Cu}\left(\mathrm{mg} \mathrm{dm}^{-3}\right)$ & - & - & 2,9 & 2,1 & 15,0 & 4,2 & 4,2 & 3,1 \\
\hline$B\left(\mathrm{mg} \mathrm{dm}^{-3}\right)$ & - & - & 0,4 & 0,5 & 0,5 & 0,4 & 0,5 & 0,5 \\
\hline $\mathrm{S}\left(\mathrm{mg} \mathrm{dm}^{-3}\right)$ & - & - & 42,5 & 9,8 & 36,2 & 23,4 & 26,2 & 14,9 \\
\hline
\end{tabular}

*Na safra da seca 2003, não foi realizada nova amostragem do solo, sendo utilizados os resultados da safra anterior. $\mathrm{PD}=$ plantio direto sobre palhada de aveia, trigo ou pousio, $\mathrm{CO}=$ sistema convencional, $\mathrm{PDT}=$ plantio direto sobre palhada de trigo, PDA = plantio direto sobre palhada de aveia, $\mathrm{PDP}=$ plantio direto sobre palhada do pousio. 


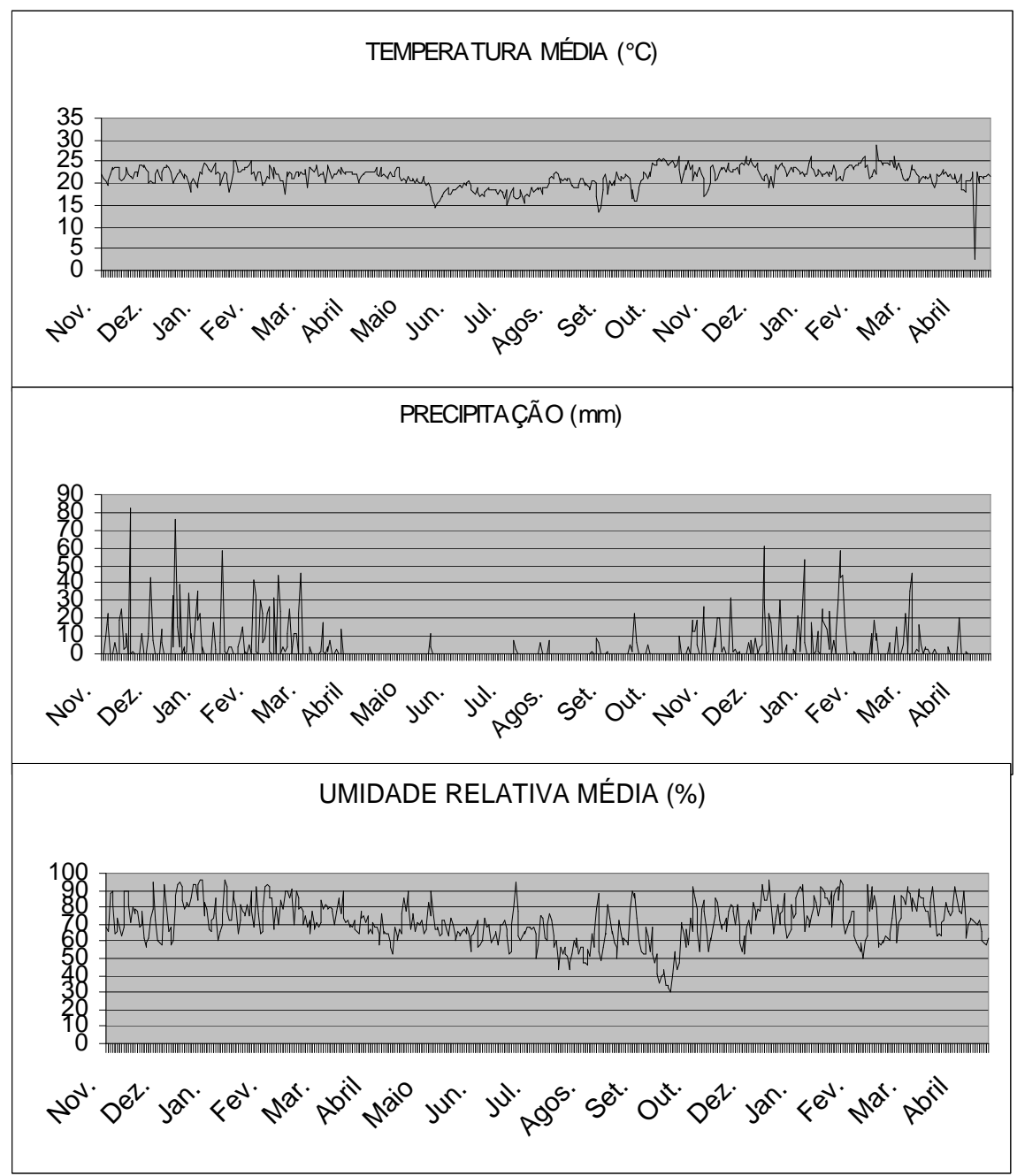

FIGURA 1 - Umidade relativa do ar, precipitação e temperatura no período de novembro/2001 a abril/2003, em Lavras, MG. Dados fornecidos pelo Setor de Agrometeorologia do Departamento de Engenharia Agrícola da UFLA.

No sistema convencional, a aração foi feita à profundidade de $25 \mathrm{~cm}$, seguida de duas gradagens. No plantio direto, uma roçadeira cortou as palhadas já dessecadas e uniformizou a sua distribuição.

A dessecação das palhadas foi realizada 15 dias antes da semeadura do feijão. Na primeira safra, empregou-se o glifosate (Roundup $3 \mathrm{~L} \mathrm{ha}^{-1}$ do pc.); na segunda e na quarta safras, o paraquat (Gramoxone 200, 2 L ha $^{-1}$ do p.c.) e, na terceira, o sulfosate (Zapp, $3 \mathrm{~L}$ $\mathrm{ha}^{-1}$ do produto comercial).

A adubação foi baseada na análise do solo (Tabela 1) e nas recomendações oficiais para a cultura do feijoeiro no Estado de Minas Gerais, considerando-se o nível 3 de tecnologia (CFSEMG, 1999). As fontes utilizadas foram o sulfato de amônio (20\% de N), o superfosfato simples $\left(18 \%\right.$ de $\left.\mathrm{P}_{2} \mathrm{O}_{5}\right)$ e o cloreto de potássio $\left(58 \%\right.$ de $\left.\mathrm{K}_{2} \mathrm{O}\right)$.

A densidade de semeadura do feijão foi de 20 sementes por metro, desbastando-se 20 dias após a semeadura para 12 plantas $\mathrm{m}^{-1}$. A profundidade de semeadura foi de 3 a $4 \mathrm{~cm}$.

O controle de plantas daninhas foi realizado em pré-emergência com metolachlor (Dual $960 \mathrm{E}, 3 \mathrm{~L} \mathrm{ha}^{-1}$ ), dois dias após a semeadura (DAS), e em pós-emergência, entre 25 e 30 DAS com fomesafen (Flex, $1 \mathrm{~L} \mathrm{ha}^{-1}$ ) nas águas 2001/2002 ou a mistura fomesafen+fluazifop-butil (Robust, $1 \mathrm{~L} \mathrm{ha}^{-1}$ ) no inverno-primavera 2002 e seca de 2003. Na safra das águas 2002/2003, o controle pósemergente foi feito por capina manual. 
TABELA 2 - Cultivares de feijão utilizadas e algumas de suas características. Lavras-MG.

\begin{tabular}{|c|c|c|c|c|}
\hline Cultivar & Origem & $\begin{array}{l}\text { Tipo de } \\
\text { grão }\end{array}$ & Hábito de crescimento & Outras características \\
\hline Talismã $^{1}$ & $\begin{array}{l}\text { UFLA/UFV/EPAMIG/EM } \\
\text { BRAPA(C II -102) }\end{array}$ & carioca & $\begin{array}{l}\text { Indeterminado tipo III } \\
\quad \text { (prostrado) }\end{array}$ & $\begin{array}{l}\text { Ciclo } 85 \text { dias, floração média } 44 \text { dias, } \\
\text { vagem na colheita amarelo-areia. }\end{array}$ \\
\hline Ouro Negro $^{2}$ & $\begin{array}{c}\text { Honduras } \\
\text { (Honduras 35) }\end{array}$ & preto & $\begin{array}{l}\text { Indeterminado tipo III } \\
\quad \text { (prostrado) }\end{array}$ & $\begin{array}{l}\text { Ciclo } 90 \text { dias, alta capacidade de fi- } \\
\text { xação simbiótica de nitrogênio, re- } \\
\text { sistente à ferrugem e antracnose, to- } \\
\text { lerante ao frio. }\end{array}$ \\
\hline Pérola $^{2}$ & $\begin{array}{l}\text { EMBRAPA } \\
\text { 720982CPL53) }\end{array}$ & carioca & $\begin{array}{l}\text { Indeterminado tipo II/III } \\
\text { (semi-ereto a prostrado) }\end{array}$ & $\begin{array}{l}\text { Ciclo } 90 \text { dias, resistente à ferrugem, } \\
\text { mancha-angular e mosaico-comum. }\end{array}$ \\
\hline Jalo $\mathrm{ESAL}^{3}$ & UFLA (ESAL 540) & jalo & $\begin{array}{l}\text { Indeterminado tipo III } \\
\quad \text { (prostrado) }\end{array}$ & $\begin{array}{l}\text { Ciclo precoce, suscetível à ferrugem, } \\
\text { antracnose e mosaico-comum. }\end{array}$ \\
\hline Carioca $^{2}$ & IAC (Seleção em SP) & carioca & $\begin{array}{l}\text { Indeterminado tipo III } \\
\quad \text { (prostrado) }\end{array}$ & $\begin{array}{l}\text { Ciclo } 90 \text { dias, suscetível à antracno- } \\
\text { se e resistente ao mosaico-comum. }\end{array}$ \\
\hline Roxão $^{4}$ & $\begin{array}{l}\text { Desconhecida (provavel- } \\
\text { mente interior de Minas) }\end{array}$ & roxo & $\begin{array}{l}\text { Indeterminado tipo III } \\
\quad \text { (prostrado) }\end{array}$ & $\begin{array}{l}\text { Ciclo } 83 \text { dias, suscetível à ferrugem } \\
\text { e mancha-angular, hipocótilo verde, } \\
\text { flor roxo-clara. }\end{array}$ \\
\hline
\end{tabular}

${ }^{1}$ Cultivar... (2002), ${ }^{2}$ Informativo Anual das Comissões Técnicas Regionais de Feijão (1998), ${ }^{3}$ Rodrigues et al. (1996), ${ }^{4}$ Observações do presente trabalho.

O controle de formigas com fipronil isca e diazinon pó (Blitz e Madaldrin 400PM, respectivamente) foi realizado três a quatro semanas após a semeadura, exceto nas águas 2002/2003. Nessa safra e na seca de 2003, houve infestação por cigarrinha-verde (Empoasca kraemeri), controlada por uma aplicação de methamidophos (Tamaron BR, $1 \mathrm{~L} \mathrm{ha}^{-1}$ ). Ainda merecem registro a infecção por fungos de solo (Fusarium solani, Rhizoctonia solani, Sclerotium rolfsii, Macrophomina phaseolina) e a observação de raízes com galhas de nematóide (Meloydogyne sp.), com maior incidência nas águas de 2002/2003, sem adoção de qualquer tipo de controle. Nessa última safra houve ainda severa ocorrência de ferrugem (Uromyces appendiculattus), controlada com uma aplicação de tebuconazole (Folicur 200 CE, 1 $\mathrm{L} \mathrm{ha}^{-1}$ ).

O experimento de inverno-primavera 2002 foi conduzido sob irrigação por aspersão convencional, com turno de rega de 3 a 4 dias. Esse mesmo turno foi empregado nas demais safras, sempre que o intervalo entre chuvas prolongava-se por mais de uma semana.

A quantidade de palha nos três sistemas de plantio direto foi estimada por meio de três amostragens de $1 \mathrm{~m}^{2}$ cada uma. $\mathrm{O}$ material de cada amostra foi acondicionado em estufa com circulação forçada de ar a $60^{\circ} \mathrm{C}$, até atingir peso constante, sendo pesado e o peso expresso em $\mathrm{t} \mathrm{ha}^{-1}$ de matéria seca. No feijoeiro, avaliaram-se o estande final e o rendimento de grãos, expressando-se esse último valor em $\mathrm{kg} \mathrm{ha}^{-1}$, após correção para $13 \%$ de umidade. Os dados do feijoeiro foram submetidos à análise de variância individual por experimento e conjunta das três primeiras safras.

\section{RESULTADOS E DISCUSSÃO}

As quantidades de palha variaram bastante, de 2,8 até $8,4 \mathrm{t} \mathrm{ha}^{-1}$ (Tabela 3). Constata-se, ainda, que em muitas das combinações de cobertura e safras não foi alcançada a quantidade de $6 \mathrm{t} \mathrm{ha}^{-1}$ de palha, considerada adequada para se obter todas as vantagens do plantio direto (ALVARENGA et al., 2001).

De maneira geral, as coberturas obtidas com as palhadas de aveia e de trigo superaram a do pousio. Observa-se, entretanto, que o comportamento das palhadas foi bastante dependente da safra em questão. Na safra das águas 2001/2002, por exemplo, quando as condições da estação de crescimento das coberturas foram aparentemente melhores, as quantidades de matéria seca da aveia e do trigo superaram as do pousio em $58 \%$ e $24 \%$, respectivamente (Tabela 3 ). Na seca de 2003, por sua vez, o ambiente certamente não favoreceu o cresci- 
mento das coberturas, proporcionando baixa produção de palhada, inclusive de aveia (Tabela 3 ).

Pela análise de variância conjunta dos dados do feijoeiro nas três primeiras safras pôde-se verificar que o rendimento de grãos foi estimado com baixa precisão. $\mathrm{O}$ erro experimental envolvido na avaliação dos efeitos dos sistemas de plantio $\left(\mathrm{CV}_{1}\right)$ foi superior a $30 \%$, valor que pode ser considerado elevado em relação aos valores normalmente obtidos em experimentos com o feijoeiro (ABREU et al., 1994). Esse fato, entretanto, pode ser, pelo menos em parte, atribuído à natureza do delineamento utilizado, o qual, embora facilite a implantação e operacionalização dos experimentos, imprime certo grau de restrição à casualização (MORAIS, 2001).

$\mathrm{O}$ estande final e o rendimento de grãos foram significativamente influenciados pela interação tripla, significando que o comportamento das cultivares de feijoeiro foi diferenciado em função dos sistemas de plantio e das safras.

Verifica-se que na safra das águas 2001/2002, as cultivares apresentaram populações de plantas que não diferiram entre si e que, na segunda safra (invernoprimavera 2002), pequenas diferenças foram detectadas no plantio convencional (Tabela 4).

Nas águas 2002/2003, as cultivares diferiram quanto ao estande final, sendo 'Ouro Negro' e 'Roxão' as cultivares que menores estandes apresentaram (Tabela 4), provavelmente por serem as únicas que não tiveram suas sementes novamente adquiridas para a semeadura dessa safra (não foram encontradas no mercado), o que se refletiu na qualidade fisiológica, germinação e emergência.

Na primeira safra, os sistemas de plantio não influenciaram o estande final das cultivares e, na segunda, as diferenças foram de pequena magnitude e não foram consistentes (Tabela 4). Na terceira safra, quando as condições climáticas (Figura 1) e fitossanitárias foram inferiores, o sistema convencional esteve sempre entre os de melhores estandes, enquanto os plantios diretos sobre palhadas do trigo e do pousio propiciaram as menores populações (Tabela 4).

Os rendimentos médios de grãos das três primeiras safras foram superiores à produtividade média brasileira, em torno de $700 \mathrm{~kg} \mathrm{ha}^{-1}$ (AGRIANUAL, 2001). Em relação à média mineira, da ordem de 900 $\mathrm{kg} \mathrm{ha}^{-1}$ (EMBRAPA, 2003), apenas o rendimento médio obtido nas águas 2002/2003 mostrou-se inferior. Pode ser inferido ainda que o fator safra modificou tanto o comportamento das cultivares dentro de cada sistema de plantio como o desempenho dos sistemas de plantio para cada cultivar (Tabela 5).

De maneira geral, as condições edafoclimáticas de cada safra (Tabela 1 e Figura 1) exerceram grande influência sobre a produtividade de grãos, cujos valores refletiram fielmente aquelas condições, as quais incluem complexa interação de fatores (ANDRADE, 1998). De acordo com esse argumento, o melhor ambiente para crescimento e produção do feijoeiro parece ter sido o da safra do inverno-primavera $2002\left(2637 \mathrm{~kg} \mathrm{ha}^{-1}\right)$, seguido das águas 2001/2002 (1078 $\left.\mathrm{kg} \mathrm{ha}^{-1}\right)$ e das águas 2002/2003 (720 kg ha $\left.{ }^{-1}\right)$. Nessa última, além das condições de alta precipitação, alta temperatura e elevada umidade do solo, a produtividade foi certamente afetada pela ocorrência de fungos de solo, nematóides das galhas e cigarrinha-verde, como já relatado.

TABELA 3 - Peso da matéria seca $\left(\mathrm{t} \mathrm{ha}^{-1}\right)$ de diferentes coberturas de solo empregadas no plantio direto do feijoeiro em quatro safras. UFLA: Lavras-MG, 2001/2003.

\begin{tabular}{lcccc}
\hline \multirow{2}{*}{ Safras } & \multicolumn{3}{c}{ Coberturas } & \multirow{2}{*}{ Média } \\
\cline { 2 - 4 } & Aveia & Trigo & Pousio & \\
\hline Água 2001/2002 & 8,4 & 6,6 & 5,3 & 6,8 \\
Inverno-primavera 2002 & 6,2 & 6,0 & 5,7 & 6,0 \\
Águas 2002/2003 & 5,1 & 4,4 & 6,6 & 5,4 \\
Seca 2003 & 4,2 & - & 2,8 & 3,5 \\
\hline Média & 5,9 & 5,6 & 5,0 & 5,5 \\
\hline
\end{tabular}


TABELA 4 - Estande final (mil plantas por hectare) em três safras de seis cultivares de feijoeiro em quatro sistemas de plantio. UFLA, Lavras-MG, 2001/2003.

\begin{tabular}{|c|c|c|c|c|c|c|}
\hline \multirow{2}{*}{ Safras } & \multirow{2}{*}{ Cultivar } & \multicolumn{4}{|c|}{ Sistemas de Plantio } & \multirow{2}{*}{ Média } \\
\hline & & Convencional & PD trigo & PD aveia & PD pousio & \\
\hline \multirow{6}{*}{$\begin{array}{c}\text { Águas } \\
2001 / 2002\end{array}$} & Talismã & 221 a A & 240 a A & 239 a A & 229 a A & 232 \\
\hline & Carioca & 236 a A & 227 a A & 229 a A & 229 a A & 230 \\
\hline & Pérola & 238 a A & 221 a A & 231 a A & 227 a A & 229 \\
\hline & Ouro Negro & 224 a A & 224 a A & 217 a A & 232 a A & 224 \\
\hline & Roxão & 225 a A & 220 a A & 229 a A & 226 a A & 225 \\
\hline & Jalo ESAL & 231 a $\mathrm{A}$ & 226 a A & 230 a $\mathrm{A}$ & 226 a A & 228 \\
\hline Média & & 229 & 226 & 229 & 228 & 228 \\
\hline \multirow{6}{*}{$\begin{array}{c}\text { Inverno } \\
2002\end{array}$} & Talismã & 223 abc A & 238 a A & 233 a $\mathrm{A}$ & 229 a A & 231 \\
\hline & Carioca & $232 \mathrm{ab} A$ & 220 a A & 231 a $\mathrm{A}$ & 222 a A & 226 \\
\hline & Pérola & 237 a A & 231 a A & 224 a A & 239 a A & 233 \\
\hline & Ouro Negro & 192 bc B & 237 a A & 231 a $\mathrm{A}$ & 231 a A & 223 \\
\hline & Roxão & 184 c B & 220 a $\mathrm{AB}$ & 231 a $\mathrm{A}$ & 224 a A & 215 \\
\hline & Jalo ESAL & $226 a b c A$ & 230 a A & 233 a A & 237 a A & 232 \\
\hline \multicolumn{2}{|l|}{ Média } & 216 & 229 & 231 & 230 & 226 \\
\hline \multirow{6}{*}{$\begin{array}{c}\text { Águas } \\
2002 / 2003\end{array}$} & Talismã & 234 a A & 190 a B & 208 a AB & 128 a C & 190 \\
\hline & Carioca & 149 bc A & 107 b B & $131 \mathrm{bcAB}$ & 133 a $\mathrm{AB}$ & 130 \\
\hline & Pérola & 142 bc B & 109 b B & 149 b A & $126 \mathrm{a} A B$ & 132 \\
\hline & Ouro Negro & $111 \mathrm{c} \mathrm{A}$ & 93 b A & $98 \mathrm{~cd} \mathrm{~A}$ & 101 a A & 101 \\
\hline & Roxão & $54 \mathrm{~d} \mathrm{~A}$ & $44 \mathrm{c} \mathrm{A}$ & $62 \mathrm{~d} \mathrm{~A}$ & $47 \mathrm{~b} \mathrm{~A}$ & 52 \\
\hline & Jalo ESAL & $172 \mathrm{~b} \mathrm{~A}$ & 171 a A & 199 a A & 110 a B & 163 \\
\hline Média & & 144 & 119 & 141 & 108 & 128 \\
\hline Média Geral & & 196 & 191 & 200 & 189 & 194 \\
\hline
\end{tabular}

Dentro de safra, nas colunas, médias seguidas da mesma letra minúscula e nas linhas de mesma letra maiúscula não diferem significativamente pelo teste de Tukey a $5 \%$ de probabilidade. 
Na safra das águas 2002/2003, quando as condições ambientais não foram satisfatórias, as cultivares praticamente não diferiram quanto à produtividade (Tabela 5). Provavelmente por causa das condições desfavoráveis de clima e/ou de solo, houve limitação do rendimento de grãos, impedindo que os genótipos expressassem o seu potencial.

Embora as safras e os sistemas de produção tenham exercido alterações de diferentes magnitudes sobre o rendimento de grãos de cada cultivar, observa-se que a 'Ouro Negro' destacou-se das demais na maioria das situações, mostrando-se a mais produtiva ou situando-se entre as de melhor desempenho (Tabela 5). As cultivares Jalo ESAL e Roxão, por seu turno, foram sempre as de pior comportamento e, no presente estudo, foram também as de maior tamanho de grãos (Tabela 5) e as mais precoces (Tabela 2). Cruz et al. (1993) já haviam verificado que cultivares de grão graúdo apresentam maior taxa de acúmulo de matéria seca no grão e menor duração do período de enchimento; daí resultarem em grãos grandes, mas com baixa produtividade. As cultivares Pérola, Carioca e Talismã, com ligeiro destaque para essa última, ficaram em posição intermediária, com rendimentos médios da ordem de 1.400 a $1.600 \mathrm{~kg} \mathrm{ha}^{-1}$ (Tabela 5).

A cv. Talismã não apresentou resultados diferenciados nos diferentes sistemas de plantio, levando a rendimentos de grãos equivalentes em todas as três safras. A cv. Ouro Negro, a mais produtiva, mostrou-se mais sensível aos sistemas de produção, os quais afetaram-lhe os rendimentos médios em duas das safras estudadas (inverno-primavera 2002 e águas 2002/2003). As demais cultivares foram influenciadas pelo sistema de plantio em pelo menos uma das safras (Tabela 5). Pelos resultados da cv. Ouro Negro, infere-se que, desde que as condições ambientais não sejam limitantes, maior produtividade é acompanhada de maior sensibilidade ao sistema de plantio, o que é corroborado pelas maiores diferenças entre sistemas de plantio na safra de invernoprimavera 2002, a mais produtiva (Tabela 5).

Em todas as situações em que houve diferenças significativas entre sistemas de plantio, a semeadura convencional sempre se mostrou inferior ao plantio direto, independente da cultura de cobertura (Tabela 5). Com esses dados, infere-se que apesar da curta duração do estudo e das baixas quantidades de palhas acumuladas nos diferentes sistemas de plantio direto (Tabela 3), esses superaram o tradicional sistema de plantio com revolvimento periódico do solo.

Ao comparar as diferentes culturas de cobertura, nota-se que no inverno-primavera de 2002 a produtivi- dade obtida no tratamento PD em pousio foi superior para a maioria das cultivares. Entretanto, nas águas 2002/2003, o tratamento PD sobre palhada de trigo foi a melhor em algumas das situações (Tabela 5). Deve ser ainda observado que esse resultado não guarda qualquer relação com as quantidades de palha estimadas nas diferentes safras (Tabela 3).

No presente estudo, apesar da significância da interação tripla (Tabela 5), verifica-se que o efeito das safras mostrou-se mais evidente que os sistemas de plantio. Esse resultado é corroborado pelos de Ramalho et al. (1993), pois, ao avaliarem genótipos de feijoeiro em dezesseis ambientes, constataram que a interação cultivar x safra foi mais expressiva que cultivar $\mathrm{x}$ local. Esse efeito é, certamente, conseqüência das diferenças de precipitação pluvial e de umidade, temperatura e aeração do solo entre as diferentes safras (ANDRADE, 1998).

Na safra de seca/2003, pela análise de variância, também evidenciou-se que o rendimento de grãos foi estimado com menor precisão. Provavelmente, conforme já discutido, esse fato deve-se, em parte, ao modelo do delineamento experimental adotado (MORAIS, 2001). O estande final e o rendimento de grãos mostraram-se influenciados pela interação cultivar $\mathrm{x}$ sistema de plantio, inferindo-se que o comportamento das cultivares de feijão foi diferenciado em cada sistema.

Observando-se as médias do estande final das cultivares nos três sistemas de plantio (Tabela 6) e considerando-se um estande ideal de 240 mil plantas por hectare, verifica-se que a cv. Carioca apresentou maior desvio, da ordem de $32,5 \%$, contra $3 \%$ a $16 \%$ das demais. Uma eventual explicação para o fato pode ser a sua suscetibilidade aos vários fungos que compõem o complexo "damping off” (ou tombamento), conforme já mencionado.

Na Tabela 6, verifica-se ainda que o plantio direto sobre pousio, apesar da menor quantidade de palha (Tabela 3), proporcionou maior média de estande. Para todas as cultivares, esse sistema foi o melhor ou, pelo menos, situou-se entre os melhores.

O rendimento de grãos, na safra da seca/2003 (Tabela 7), foi inferior ao das águas 2001/2002 e, principalmente, ao do inverno-primavera/2002, mas pode ser equiparado ao das águas 2002/2003. Certamente, o ambiente teve fatores limitantes à expressão do potencial das cultivares. A baixa disponibilidade hídrica, provocada pelos intervalos de até quatro dias entre as irrigações, e temperaturas abaixo de $21^{\circ} \mathrm{C}$, considerada ótima para o sul de Minas, por ocasião do enchimento do grão, podem ter sido os fatores que contribuíram para esses resultados. 
TABELA 5 - Rendimento de grãos $\left(\mathrm{kg} \mathrm{ha}^{-1}\right)$ em três safras de seis cultivares de feijoeiro em quatro sistemas de plantio. UFLA, Lavras-MG, 2001/2003.

\begin{tabular}{|c|c|c|c|c|c|c|}
\hline \multirow{2}{*}{ Safras } & \multirow{2}{*}{ Cultivar } & \multicolumn{4}{|c|}{ Sistemas de Plantio } & \multirow{2}{*}{ Média } \\
\hline & & Convencional & PD trigo & PD aveia & PD pousio & \\
\hline \multirow{6}{*}{$\begin{array}{c}\text { Águas } \\
2001 / 2002\end{array}$} & Talismã & $1259 \mathrm{ab} A$ & $1214 \mathrm{ab} A$ & $1272 \mathrm{ab} A$ & $1256 \mathrm{ab} A$ & 1250 \\
\hline & Carioca & $937 \mathrm{ab} A$ & $869 \mathrm{~b} \mathrm{~A}$ & $843 \mathrm{~b} \mathrm{~A}$ & $1024 \mathrm{ab} A$ & 918 \\
\hline & Pérola & $1113 \mathrm{ab} A$ & 463 c A & $668 \mathrm{~b} \mathrm{~A}$ & $682 \mathrm{c} \mathrm{A}$ & 732 \\
\hline & Ouro Negro & 1663 a A & 1826 a A & 1812 a A & 1708 a A & 1752 \\
\hline & Roxão & 794 b A & $1024 \mathrm{bc} \mathrm{A}$ & $810 \mathrm{~b} \mathrm{~A}$ & 860 c A & 872 \\
\hline & Jalo ESAL & $822 \mathrm{~b} \mathrm{~A}$ & $1106 \mathrm{bc} \mathrm{A}$ & 952 b A & 858 с A & 935 \\
\hline Média & & 1098 & 1084 & 1060 & 1065 & 1077 \\
\hline \multirow{6}{*}{$\begin{array}{c}\text { Inverno } \\
2002\end{array}$} & Talismã & 2508 a A & $2355 \mathrm{bc} \mathrm{A}$ & 2583 a A & $3052 \mathrm{ab} \mathrm{A}$ & 2625 \\
\hline & Carioca & 2775 a $A B$ & $2325 \mathrm{bc} \mathrm{B}$ & 2763 a $A B$ & $3191 \mathrm{ab} A$ & 2764 \\
\hline & Pérola & 2423 a A & $2965 \mathrm{ab} A$ & 2515 a A & $3055 \mathrm{ab} A$ & 2740 \\
\hline & Ouro Negro & 2372 a B & 3080 a $\mathrm{AB}$ & 3179 a A & 3443 a A & 3019 \\
\hline & Roxão & $1360 \mathrm{~b} \mathrm{C}$ & 2121 c BC & 2837 a $\mathrm{AB}$ & 3441 a A & 2440 \\
\hline & Jalo ESAL & 1399 b B & 2191 c A & 2644 a A & $2715 \mathrm{~b} \mathrm{~A}$ & 2238 \\
\hline Média & & 2140 & 2506 & 2754 & 3150 & 2638 \\
\hline \multirow{6}{*}{$\begin{array}{c}\text { Águas } \\
2002 / 2003\end{array}$} & Talismã & 662 a A & 1242 a A & 1078 a A & 794 a A & 944 \\
\hline & Carioca & 444 a A & 1193 a A & 741 a A & 456 a A & 709 \\
\hline & Pérola & 319 a B & $1123 \mathrm{ab} A$ & 1032 a AB & 415 a $\mathrm{AB}$ & 722 \\
\hline & Ouro Negro & 544 a A & 1278 a A & 967 a A & 799 a A & 897 \\
\hline & Roxão & 279 a A & $603 \mathrm{ab} A$ & 686 a A & 477 a A & 511 \\
\hline & Jalo ESAL & 216 a A & $450 \mathrm{~b} \mathrm{~A}$ & 729 a A & 756 a A & 538 \\
\hline Média & & 411 & 981 & 872 & 616 & 720 \\
\hline Média Geral & & 1216 & 1524 & 1562 & 1610 & 1478 \\
\hline
\end{tabular}

Dentro de cada safra, nas colunas, médias seguidas por mesma letra minúscula e nas linhas por mesma letra maiúscula não diferem significativamente pelo teste de Tukey a $5 \%$ de probabilidade. 
TABELA 6 - Estande final (mil plantas $\mathrm{ha}^{-1}$ ) de seis cultivares de feijoeiro em cada sistema de plantio na safra da seca/2003. UFLA, Lavras-MG, 2003.

\begin{tabular}{lcccc}
\hline \multirow{2}{*}{ Cultivar } & \multicolumn{3}{c}{ Sistema de plantio } & \multirow{2}{*}{ Média } \\
\cline { 2 - 4 } & Convencional & PD Aveia & PD Pousio & \\
\hline Talismã & $229 \mathrm{a} \mathrm{A}$ & $231 \mathrm{a} \mathrm{A}$ & $236 \mathrm{a} \mathrm{A}$ & 232 \\
Carioca & $132 \mathrm{c} \mathrm{B}$ & $186 \mathrm{c} \mathrm{A}$ & $168 \mathrm{~b} \mathrm{~A}$ & 162 \\
Pérola & $189 \mathrm{~b} \mathrm{~B}$ & $197 \mathrm{abc} \mathrm{B}$ & $227 \mathrm{a} \mathrm{A}$ & 204 \\
Ouro Negro & $202 \mathrm{ab} \mathrm{A}$ & $191 \mathrm{bc} \mathrm{A}$ & $211 \mathrm{a}$ & 201 \\
Roxão & $211 \mathrm{ab} \mathrm{B}$ & $225 \mathrm{ab} \mathrm{AB}$ & $239 \mathrm{a} \mathrm{A}$ & 225 \\
Jalo ESAL & $234 \mathrm{a} \mathrm{A}$ & $229 \mathrm{a} \mathrm{A}$ & $210 \mathrm{a} \mathrm{A}$ & 224 \\
\hline Médias & 199 & 210 & 215 & 208 \\
\hline
\end{tabular}

Médias seguidas da mesma letra minúscula na coluna e da mesma letra maiúscula na linha não diferem significativamente pelo teste de Tukey a $5 \%$ de probabilidade.

TABELA 7 - Rendimento de grãos $\left(\mathrm{kg} \mathrm{ha}^{-1}\right)$ de seis cultivares de feijoeiro em três sistemas de plantio na safra da seca/2003. UFLA, Lavras-MG, 2003.

\begin{tabular}{lcccc}
\hline \multirow{2}{*}{ Cultivar } & \multicolumn{3}{c}{ Sistema de Plantio } & \multirow{2}{*}{ Média } \\
\cline { 2 - 4 } & Convencional & PD Aveia & PD Pousio & \\
\hline Talismã & $897 \mathrm{a} \mathrm{A}$ & $594 \mathrm{abc} \mathrm{B}$ & $817 \mathrm{bc} \mathrm{AB}$ & 769 \\
Carioca & $457 \mathrm{~b} \mathrm{AB}$ & $369 \mathrm{c} \mathrm{B}$ & $638 \mathrm{c} \mathrm{A}$ & 488 \\
Pérola & $889 \mathrm{a} \mathrm{A}$ & $507 \mathrm{bc} \mathrm{B}$ & $815 \mathrm{bc} \mathrm{A}$ & 737 \\
Ouro Negro & $917 \mathrm{a} \mathrm{A}$ & $664 \mathrm{ab} \mathrm{B}$ & $905 \mathrm{abc} \mathrm{A}$ & 828 \\
Roxão & $793 \mathrm{a} \mathrm{B}$ & $769 \mathrm{ab} \mathrm{B}$ & $1122 \mathrm{a} \mathrm{A}$ & 895 \\
Jalo ESAL & $769 \mathrm{a} \mathrm{B}$ & $856 \mathrm{a} \mathrm{AB}$ & $1013 \mathrm{ab} \mathrm{A}$ & 880 \\
\hline Médias & 787 & 627 & 885 & 766 \\
\hline
\end{tabular}

Médias seguidas da mesma letra minúscula na coluna e da mesma letra maiúscula na linha não diferem significativamente pelo teste de Tukey a $5 \%$ de probabilidade.

No plantio direto sobre resteva do pousio, a maior produtividade foi alcançada pela cultivar Roxão (Tabela 7), seguida da Jalo ESAL e Ouro Negro, as quais não diferiram entre si. Quando cultivada no sistema convencional, ou no plantio direto sobre aveia, a cv. Carioca apresentou o pior desempenho.
Uma provável explicação para a maior produtividade do tratamento plantio direto sobre pousio pode ser a baixa relação $\mathrm{C} / \mathrm{N}$ da flora do pousio, constituída basicamente de picão-preto (Bidens pilosa L.), nabiça (Raphanus sativus L.), apaga-fogo (Alternanthera tenella Colla), caruru (Amaranthus deflexus L.) e buva (Comellina bengalensis Cabrera), algumas dessas com 
relação $\mathrm{C} / \mathrm{N}$ inferior a 20 (MONEGAT, 1991), o que tornaria mais rápida a decomposição da palhada, liberando nutrientes mais prontamente ao feijoeiro ou imobilizando menos o $\mathrm{N}$ do solo.

Observa-se também que, na safra da seca, as produções das cultivares em plantio convencional superaram as obtidas no tratamento com palhada de aveia. Como nessa safra as palhadas ficaram muito aquém das quantidades consideradas adequadas (em torno de $6 \mathrm{t} \mathrm{ha}^{-1}$ ), reduziram-se as vantagens do plantio direto. Outra hipótese para esse comportamento inferior do plantio direto sobre aveia seria um possível efeito alelopático da palhada sobre o feijoeiro, por meio da liberação de compostos do metabolismo secundário, seja pela lavagem, volatilização e exsudação de raízes, seja pela decomposição dos seus resíduos (RICE, 1974).

\section{CONCLUSÕES}

O rendimento de grãos e o estande das cultivares de feijoeiro são influenciados pelo sistema de plantio e, principalmente, pela safra.

As cultivares com maior tamanho de grãos (Jalo ESAL e Roxão) tiveram menor produtividade de grãos.

Na maioria das situações, em sistema de plantio direto, as cultivares de feijoeiro apresentaram rendimentos superiores ou equivalentes aos do sistema convencional

Quando a produção de matéria seca pela cultura de cobertura é muito pequena, o plantio direto sobre resteva do pousio proporciona maior rendimento de grãos pelo feijoeiro.

\section{REFERÊNCIAS BIBLIOGRÁFICAS}

ABREU, A. de F. B.; RAMALHO, M. P. A. P.; SANTOS, J. B. dos; MARTINS, L. A. Progresso do melhoramento genético do feijoeiro: nas décadas de setenta e oitenta nas regiões Sul e Alto Paranaíba em Minas Gerais. Pesquisa Agropecuária Brasileira, Brasília, v. 23, n. 1, p. 105-112, jan. 1994.

AGRIAnUal. Anuário da Agricultura Brasileira. São Paulo: FNP, 2001.432 p.

ALVARENGA, R. C.; CABEZAS, W. A. L.; CRUZ, J. C.; SANTANA, D. P. Plantas de cobertura de solo para sistema plantio direto. Informe Agropecuário, Belo Horizonte, v. 22, n. 208, jan./fev. 2001.
ANDRADE, M. J. B. Clima e solo. In: VIEIRA, C. (Ed.). Feijão: aspectos gerais e cultura no Estado de Minas. Viçosa: UFV, 1998.

BRASIL. Ministério da Agricultura. Normais climatológicos: Minas Gerais, Espírito Santo, Rio de Janeiro. Brasília, 1992. 84 p.

CIRINO, V. D.; LOLLATO, M. A.; OLIARI, L. Cultivar. In: INSTITUTO AGRONÔMICO DO PARANÁ. Feijão: tecnologia de produção. Londrina, 2000. 115 p. (IAPAR. Informe de Pesquisa, 135).

COMISSÃO DE FERTILIDADE SOLO DO ESTADO DE MINAS GERAIS. Recomendações para o uso de corretivos e fertilizantes em Minas Gerais: $5^{\text {a }}$ aproximação. Viçosa: UFV, 1999. 359 p.

CRUZ, J. L.; RAMALHO, M. A. P.; MARTINS, L. A.; PELANCANI, C. R. Relação entre rendimento, componentes primários de rendimento e parâmetros de enchimento dos grãos do feijoeiro. Revista Brasileira de Fisiologia Vegetal, Londrina, v. 5, p. 15962, 1993.

CULTIVAR de feijão Talismã. Sete Lagoas: UFLA/UFV/EMBRAPA/EPAMIG, 2002. Folder.

EMPRESA BRASILEIRA DE PESQUISA AGROPECUÁRIA. Sistema brasileiro de classificação de solos. Brasília, 1999. 412 p.

EMPRESA BRASILEIRA DE PESQUISA AGRIPECUÁRIA, Sistema de produção do feijoeiro: a cultura do _ _ feijoeiro. _ _ _ Disponível em: hhttp://Www.cnpaf.embrapa. by 2003.

INFORMATIVO ANUAL DAS COMISSÕES TÉCNICAS REGIONAIS DE FEIJÃO. Cultivares de feijão indicadas para plantio: safra 1998/1999. Goiânia: EMBRAPA-CNPAF, 1998. 29 p.

MACHADO, L. A. Z. Aveia: forragem e cobertura do solo. Dourados, MS: EMBRAPA Agropecuária Oeste, 2000. 16 p. (Coleção Sistema de Plantio Direto, $4)$.

MONEGAT, C. Plantas de cobertura do solo: características e manejo em pequenas propriedades. Chapecó: Ed. do Autor, 1991. 337 p. 
MORAIS, A. R. Estatística experimental: uma introdução aos delineamentos e análise de experimentos. Lavras: UFLA, 2001.

OLIVEIRA, T. K. de. Plantas de cobertura em cultivo solteiro e consorciado e seus efeitos no feijoeiro e no solo em plantio direto. 2001. 109 p. Dissertação (Mestrado em Fitotecnia) - Universidade Federal de Lavras, Lavras, 2001.

RAMALHO, M. A. P.; ABREU, A. F. B.; RIGETTO, G. U. Interação de cultivares de feijão por época de semeadura em diferentes localidades no Estado de Minas Gerais. Pesquisa Agropecuária Brasileira, Brasília, v. 28, n. 10, p. 1183-1189, out. 1993.
RICE, E. L. Allelopathy. New York: Academic, 1974. $433 \mathrm{p}$.

RODRIGUES，J. R. M.; ANDRADE， M. J. B.; CARVALHO, J. G. Resposta de cultivares de feijão (Phaseolus vulgaris L.) a doses de molibdênio aplicadas via foliar. Ciência e Agrotecnologia, Lavras, v. 20, n. 3, p. 323-333, jul./set. 1996.

SILVA, D. B. Trigo para o abastecimento familiar: do plantio à mesa. Brasília, DF: EMBRAPA-SPI; Planaltina: EMBRAPA-CPAC, 1996. 